\title{
Hypoglycaemic activity of Smilax canellifolia Mill. rhizomes: a bioassay-guided isolation and identification of synergistic compounds
}

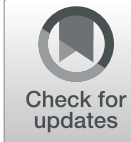

Davia A. Peddie', Sophia J. Bryan', Sheena Francis ${ }^{2}$ and Ruby L. Alexander-Lindo ${ }^{1 *}$ (D)

\begin{abstract}
Background: Smilax canellifolia Mill. is a native shrub used in commercial root tonics as an aphrodisiac, stimulant, and pain reliever. Traditional medicine incorporates the rhizomes of $S$. canellifolia for the treatment of anaemia, rheumatoid arthritis, and diabetes in Jamaica and its diaspora. In particular, the use of this plant in the management of diabetes has yet to receive any scientific evaluation. In this study, the hexane crude extract of S. canellifolia rhizomes $(\mathrm{SCH})$ was investigated to determine its hypoglycaemic activity in normal Sprague-Dawley rats and to identify the compounds contributing to this activity.

Methods: The hypoglycaemic compounds were isolated using bioactivity-guided purification which involved hypoglycaemic screening using an Oral Glucose Tolerance Test (via intravenous administration of SCH and its fractions). Purification was performed using column chromatography, and the bioactive fractions were elucidated using spectroscopic techniques (IR; GC-MS; ${ }^{1} \mathrm{H}$ NMR and ${ }^{13} \mathrm{C}$ NMR).

Results: Administration of $\mathrm{SCH}$ at $50 \mathrm{mg} / \mathrm{kg}$ body weight (BW) to normal S-D rats produced a reduced glycaemic response, notably from the 90 to the 150-min intervals when compared with the control, dimethyl sulfoxide $(p<$ 0.05). Purification of this extract yielded four main fractions, $\mathrm{SCH} 1-\mathrm{SCH} 4$, of which $\mathrm{SCH} 3$ and $\mathrm{SCH} 4$ displayed significant hypoglycaemia. Further purification of both $\mathrm{SCH} 3$ and $\mathrm{SCH} 4$ led to the isolation of sub-fractions $\mathrm{SCH} 3.6$ and $\mathrm{SCH} 4.2$, respectively. Using spectroscopic techniques stigmasterol (1) and $\beta$-sitosterol (2) from SCH3.6; and the fatty acids palmitic acid (3), oleic acid (4), and stearic acid (5) from SCH4.2 were identified as the major compounds with significant hypoglycaemic activities comparable to that of glibenclamide.

Conclusion: This study demonstrates that the rhizomes of Smilax canellifolia contain several bioactive constituents that are responsible for its hypoglycaemic activity and may be beneficial in the management of hyperglycaemia and complications associated with diabetes.
\end{abstract}

Keywords: Smilax canellifolia Mill., Smilacaceae, Hypoglycaemic activity, Fatty acids, Phytosterols, GC-MS, Hexane crude extract, Sprague-Dawley rats

\footnotetext{
* Correspondence: lisa.lindo@uwimona.edu.jm

${ }^{1}$ Department of Basic Medical Sciences, Faculty of Medical Sciences, The

University of the West Indies (UWI), Mona, Kingston 7, Jamaica

Full list of author information is available at the end of the article
}

\section{Springer Open}

(c) The Author(s). 2021 Open Access This article is licensed under a Creative Commons Attribution 4.0 International License, which permits use, sharing, adaptation, distribution and reproduction in any medium or format, as long as you give appropriate credit to the original author(s) and the source, provide a link to the Creative Commons licence, and indicate if changes were made. The images or other third party material in this article are included in the article's Creative Commons licence, unless indicated otherwise in a credit line to the material. If material is not included in the article's Creative Commons licence and your intended use is not permitted by statutory regulation or exceeds the permitted use, you will need to obtain permission directly from the copyright holder. To view a copy of this licence, visit http://creativecommons.org/licenses/by/4.0/. 


\section{Background}

It has been established that traditional and complementary medicine has had an intensified resurgence during the past decade. This has been due to an increase in the accessibility and acceptability of nutraceuticals, as well as a renewed focus on self-healing and preventative therapy [1]. The cost and availability of conventional drugs used to treat diabetes, and the belief in reduced toxicity from plant medicines have also stressed the demand for herbal or natural remedies [2]. Continuous research has therefore been encouraged to validate and integrate herbal alternatives into healthcare systems especially in countries with East Asian and African medicinal influences [1,3-6].

Smilax canellifolia Mill. (S. canellifolia) is a member of the Liliaceae family and the Smilax genus, comprising over 350 species. In Jamaica, S. canellifolia is known as Smilax balbisiana, which has recently been identified as the illegitimate synonym [7]. This native shrub is found widely cultivated in the woodlands of the Cockpit Country, Jamaica. The rhizomes of S. canellifolia, commonly known as Chainy Root, are used as a staple ingredient in Jamaica's traditional "Roots" tonics $[8,9]$. S. canellifolia is a climbing shrub, with brambled and thorny tendrilclimbing vines that can grow up to $50 \mathrm{~m}$ long. These woody vines sprout from a thick basal rhizome that is deep red/brown in colour. The basal leaves are broad and ovate, while the terminal leaflets are lanceolate or elliptical; these leaves are often paired tendrils emerging from the base of the petiole. Its flowers are small and green, while the berries range from reddish-purple to black and are $5-7 \mathrm{~mm}$ in diameter $[9,10]$. The rhizomes are believed to be an aphrodisiac used to improve impotence and increase energy. Chainy Root is also used in folklore medicine to treat anaemia, analgesia, rheumatoid arthritis, and diabetes [11, 12]. Other Smilax species have been found to display considerable ethnopharmacological activities including antioxidant, antidiabetic, hypotensive and anti-inflammatory effects [13-18]. However, along with the variation in species, the plant parts and solvents used to obtain the extracts that have been investigated, the extract used to produce significant hypoglycaemic effects were different from those used in our research. These reports also failed to explicitly identify the active naturally occurring compounds responsible for the hypoglycaemic or antidiabetic effects observed $[14,16,18]$. The crude extracts of S. canellifolia rhizomes have previously been reported to possess significant hypoglycaemic potential in animals $[19,20]$. Considering these findings, this investigation focused on isolating and identifying the bioactive compounds that contributed to the hypoglycaemic activity of $S$. canellifolia rhizomes in Sprague-Dawley rats. It is anticipated that these findings will expand the potential use of $S$. canellifolia rhizomes for the management of diabetes and possibly, its inherent complications.

\section{Material and methods \\ Chemicals and reagents}

All reference standards were purchased from SigmaAldrich (St. Louis, USA). Dimethyl sulfoxide (DMSO) was purchased from Sigma-Aldrich (St. Louis, USA). All other solvents were purchased from Pharmco-Aaper (Ontario, Canada) and were of analytical grade.

\section{Plant material}

S. canellifolia rhizomes were collected in March 2016 from Accompong, St. Elizabeth, Jamaica. A sample of the rhizome was authenticated at the University of the West Indies (UWI), Mona Herbarium with an assigned Voucher number, 3633.

\section{Screening for Hypoglycaemic activity Animals}

Normoglycaemic Sprague-Dawley (S-D) rats (150-200 g; $n=5$ per group) of mixed sexes were obtained from the UWI, Basic Medical Sciences Animal House (Mona, Jamaica). Animals were housed in stainless steel cages inside a ventilated room with an alternate $12 \mathrm{~h}$ dark/light period. The animals had free access to water and a standard laboratory diet (LabDiet 500, MO, USA). All animal experiments were approved by the UWI, Mona Campus Research Ethics Committee (Reference No. AN, 8, 14/15).

\section{Experimental design; Oral glucose tolerance test (OGTT)}

The OGTT was performed using a modified method [21]. The rats were weighed then fasted overnight (approximately $12 \mathrm{~h}$ ) before experimentation, and water was provided ad libitum.

An incision was made at the tip of the animal's tail to obtain an initial fasting blood glucose reading. The preweighed crude or purified hexane extract $(10-50 \mathrm{mg} / \mathrm{kg}$ body weight $/ \mathrm{BW}^{1}$ ) was dissolved in the vehicle, DMSO $(0.3 \mathrm{~mL})$, and administered intravenously (i.v.). Afterwards, blood glucose readings were measured at 30 and 60-min post-administration. Subsequently, a glucose load of $1.75 \mathrm{~g} / \mathrm{kg}$ BW was administered by oral gavage. Blood glucose readings were taken at 30-min intervals for a further two and a half (2.5) hours using the ACCUChek Active Blood Glucose Monitoring System.

\section{Extraction and purification of hexane crude extract $(\mathrm{SCH})$} The shade-dried $\left(\sim 28^{\circ} \mathrm{C}\right)$ and powdered rhizomes $(7.5$ $\mathrm{kg}$ ) were extracted with hexane. The plant material was

\footnotetext{
${ }^{1}$ The dosage required to observe the hypoglycaemic effect was lowered after each stage of the purification process from $50 \mathrm{mg} / \mathrm{kg}$ to $25 \mathrm{mg} / \mathrm{kg}$ then to $10 \mathrm{mg} / \mathrm{kg}$ body weight.
} 
initially saturated with hexane $(2 \mathrm{~L})$ at room temperature for two separate eight (8) hour periods and one twentyfour (24) hour period. Fresh solvent (1 L) was added for each treatment period, and the filtrates were collected and concentrated using rotary evaporation. The hexane crude extract was weighed $(16.5 \mathrm{~g})$ and the recovery percentage $(0.22 \%)$ was determined.

The hexane crude extract from the rhizomes of $S$. canellifolia $(\mathrm{SCH})$ was obtained as a gold oily residue and displayed significant hypoglycaemic activity during an OGTT. TLC analysis showed that several unresolved compounds were present. The extract $(\mathrm{SCH}, 16.24 \mathrm{~g})$ was subjected to column chromatography $(30 \times 6.5 \mathrm{~cm}$; $200-425$ mesh) and eluted with gradient Hex - EtOAc (90:10 to $0: 100, \mathrm{v} / \mathrm{v})$ solvent system, collecting $150 \mathrm{~mL}$ volumes. The eluted fractions were later pooled based on the similarity of their Thin-layer chromatography (TLC) profiles to afford four main fractions designated SCH1 (0.24 g), SCH2 (7.52 g), SCH3 (3.17 g) and SCH4 $(1.73 \mathrm{~g})$. The spots were visualized under white light, UV light, and after spraying with $10 \%$ sulfuric acid reagent.

The main fractions were subjected to hypoglycaemic screening (OGTT), where $\mathrm{SCH} 3$ and $\mathrm{SCH} 4$ displayed significant hypoglycaemic activity and were subjected to further purification.

$\mathrm{SCH} 3(2.31 \mathrm{~g})$ was separated using silica gel column $(140 \mathrm{~g})$ and eluted with a petroleum ether - EtOAc (90: 10 to $10: 90, \mathrm{v} / \mathrm{v}$ ) eluent, collecting $40 \mathrm{~mL}$ volumes to obtain 38 fractions in total. TLC comparisons afforded nine sub-fractions: SCH3.1 (0.02 g), SCH3.2 (0.48 g), SCH3.3 (0.78 g), SCH3.4 (0.26 g), SCH3.5 (0.32 g), SCH3.6 (0.18 g), SCH3.7 (0.20 g), SCH3.8 (0.03 g) and SCH3.9 (0.04 g). Sub-fractions SCH 3.1, SCH3.3, SCH3.6 and $\mathrm{SCH} 3.8$ were subjected to biological assay (bioassay) screening using an OGTT.

Fraction $\mathrm{SCH} 4(0.63 \mathrm{~g})$ was subjected to further purification using silica gel $(63 \mathrm{~g})$ and eluted with gradient mixtures of Hex - EtOAc (90:10 to 0:100, v/v). Elution was monitored by TLC and profile comparison produced six sub-fractions: SCH4.1 (0.24 g), SCH4.2 (0.13 g), SCH4.3 (0.02 g), SCH4.4 (0.03 g), SCH4.5 (0.04 g) and SCH4.6 (0.17 g). Sub-fractions SCH4.1 and SCH4.2 were selected due to their recovery percentage and screened for hypoglycaemic activity.

After the bioassay (OGTT), sub-fractions SCH3.6 and $\mathrm{SCH} 4.2$ demonstrated significant hypoglycaemic activity. They were subjected to spectroscopic (IR, ${ }^{13} \mathrm{C}$ NMR, and ${ }^{1} \mathrm{H}$ NMR) and spectrometric (GC-MS) analyses to elucidate their bioactive constituents.

Spectroscopic analysis and structural identification of $\mathrm{SCH}$ sub-fractions

Column chromatography was carried out using silica gel $60 \AA$ (200 - 425 mesh; Sigma-Aldrich, St. Louis, USA).
TLC was carried out on normal phase silica gel $60 \mathrm{~F}_{254}$ on pre-coated plastic plates (Sigma-Aldrich, St. Louis, USA), using $5 \%$ sulfuric acid spray after heating or ultraviolet (UV) light ( $254 \mathrm{~nm}$ and $365 \mathrm{~nm}$ ) for visualization.

Infrared (IR) spectra were obtained using the Nicolet iS10 FTIR spectrometer with ATR accessories. ${ }^{13} \mathrm{C}$ NMR and ${ }^{1} \mathrm{H}$ NMR spectra were recorded on a Bruker DRX$500 \mathrm{MHz}$ and DRX-200 MHz spectrometer (for 1D and 2D respectively) in deuterated chloroform. Chemical shifts $(\delta)$ were expressed in parts per million $(\mathrm{ppm})$ with reference to tetramethylsilane (TMS).

Gas Chromatography-Mass Spectroscopy analyses were performed using a DB-1701 GC capillary column (30 mm, $0.25 \mathrm{~mm}$ i.d., $0.25 \mu \mathrm{m}$ film thickness) on an Agilent $6890 \mathrm{~N}$ gas chromatograph (GC) equipped with an Aligent 5973 N Mass Selective Detector, using helium carrier gas at a flow rate of $1.2 \mathrm{~mL} \mathrm{~min}^{-1}$. A ramped temperature program was employed for the oven, starting at $80^{\circ} \mathrm{C}$ at a rate of $2{ }^{\circ} \mathrm{C} \mathrm{min}^{-1}$ for $10 \mathrm{~min}$. The samples were reconstituted in chloroform $(1 \mu \mathrm{L})$ and injected in splitless mode at $250{ }^{\circ} \mathrm{C}$. Mass spectra operations were performed in electron impact $\left(\mathrm{EI}^{+}\right)$mode at $70 \mathrm{eV}$. The chromatogram was acquired in total ion current (TIC), and the data was given in $\mathrm{m} / \mathrm{z}$ values. Derivatization was done using Bis-(trimethylsilyl)-trifluoroacetamide (BSTFA). All preliminary identifications were obtained using the NIST/EPA/NIH Mass Spectral Database (version NBS75K.L). The compounds identified were then confirmed by comparison of their retention indices and mass spectra with those of the authenticated standards under the same conditions. The relative ratio of the compounds identified was computed from the GC area percentage and excluded correction factors. All chemical structures were constructed using $\mathrm{ACD} /$ ChemSketch software (ACD/Labs version 2019).

\section{Statistical analysis}

The results were presented as mean \pm standard error of the mean (SEM). Statistical analysis was carried out using a statistical software (SPSS, Version 22, Chicago, IL, USA) to perform the Student's $t$-test. Values were considered statistically significant at $p<0.05$.

\section{Results \\ Hypoglycaemic screening}

The effect of Smilax canellifolia rhizomes hexane crude extract $(\mathrm{SCH})$ and its semi-purified fractions on blood glucose (BG) concentration were evaluated using an Oral Glucose Tolerance Test (OGTT). It was evident that the control (DMSO; vehicle) produced a glucose tolerance curve demonstrative of a typical response to an oral glucose load. Its administration had a characteristic glycaemic peak at the 90-min interval, followed by a general decrease due to the action of insulin (Fig. 1a). 
Intravenous administration of $\mathrm{SCH}$, at $50 \mathrm{mg} / \mathrm{kg} \mathrm{BW}$ was able to produce a significant reduction in BG levels throughout the OGTT when compared with the control, DMSO. Before the oral administration of glucose, a hypoglycaemic response was observed during the fasted state, that is, at the 30 and 60 -min intervals $(p<0.05)$. This reduction persisted post-glucose administration from the 90 -min interval $(4.31 \pm 0.34 \mathrm{mmol} / \mathrm{L}$ vs. $5.74 \pm$ $0.14 \mathrm{mmol} / \mathrm{L} ; p=0.017)$ up to the 150 -min interval $(3.6 \pm 0.53 \mathrm{mmol} / \mathrm{L} \quad$ vs. $5.10 \pm 0.30 \mathrm{mmol} / \mathrm{L} ; \quad p=0.035)$ when compared with the control. Consequently, the semi-purified fractions of SCH (SCH1 - SCH4; $25 \mathrm{mg}$ / $\mathrm{kg} \mathrm{BW)} \mathrm{also} \mathrm{displayed} \mathrm{varying} \mathrm{hypoglycaemic} \mathrm{responses,}$ when administered intravenously. SCH1 improved glucose tolerance at the 120-min interval when compared with the control $(p<0.05$; Fig. 1a). However, it was evident that both $\mathrm{SCH} 3$ and $\mathrm{SCH} 4$ exerted the most notable hypoglycaemic effects (Fig. 1b). SCH3 was able to show a significant reduction in BG levels at the 90-min interval $(4.30 \pm 0.42 \mathrm{mmol} / \mathrm{L}$ vs. $5.74 \pm 0.14 \mathrm{mmol} / \mathrm{L} ; p=$ $0.036)$, and at the 120 -min interval $(4.46 \pm 0.30 \mathrm{mmol} / \mathrm{L}$ vs. $5.49 \pm 0.23 \mathrm{mmol} / \mathrm{L} ; p=0.026)$ when compared with the control (Fig. 1b). Similarly, SCH4 displayed hypoglycaemic activity from the 90-min interval (4.33 \pm $0.52 \mathrm{mmol} / \mathrm{L}$ vs. $5.74 \pm 0.14 \mathrm{mmol} / \mathrm{L} ; p=0.023)$ up to the 180 - $\mathrm{min}$ interval $(3.39 \pm 0.45 \mathrm{mmol} / \mathrm{L}$ vs. $5.26 \pm 0.32$ $\mathrm{mmol} / \mathrm{L} ; \quad p=0.037)$. Further investigation into the hypoglycaemic potential displayed by $\mathrm{SCH} 3$ and $\mathrm{SCH} 4$ led to their purification, which afforded several subfractions, SCH3.1 - SCH3.9 and SCH4.1 - SCH4.6, respectively.

The screening of $\mathrm{SCH} 3.1, \mathrm{SCH} 3.3, \mathrm{SCH} 3.6$, and $\mathrm{SCH} 3.8$ (10 mg/kg BW via intravenous administration) obtained from SCH3 indicated that all except SCH3.6 had no significant effect on BG levels when compared with the control $(p>0.05$; Fig. 2). Fasted state hypoglycaemia was observed following the administration of SCH3.6 at the 30 - $\mathrm{min}(2.38 \pm 0.54 \mathrm{mmol} / \mathrm{L}$ vs. $5.05 \pm 0.28 \mathrm{mmol} / \mathrm{L} ; p=0.002)$ and $60-\mathrm{min}(2.40 \pm 0.50$ $\mathrm{mmol} / \mathrm{L}$ vs. $4.59 \pm 0.21 \mathrm{mmol} / \mathrm{L} ; \quad p=0.003$ ) intervals when compared with the control. Remarkably, postprandial hypoglycaemia was observed which persisted throughout the experiment, up to the 210-min interval $(1.96 \pm 0.37 \mathrm{mmol} / \mathrm{L}$ vs. $4.98 \pm 0.43 \mathrm{mmol} / \mathrm{L} ; p=0.001)$. A comparison of $\mathrm{SCH} 3.6$ with the commercial hypoglycaemic agent, glibenclamide $(5 \mathrm{mg} / \mathrm{kg} \mathrm{BW})$, showed a similar hypoglycaemic response in the fasted and postprandial state, $(p>0.05$; Fig. 2$)$. When SCH3.1, SCH3.3 and SCH3.8 were compared with glibenclamide, all were significantly different $(p<0.05$ : Fig. 2$)$.

SCH4.1 and SCH4.2 (10 mg/kg BW) obtained from $\mathrm{SCH} 4$ were screened and found to display hypoglycaemic activity (Fig. 3). When administered intravenously, $\mathrm{SCH} 4.1$ led to a transient lowering in the BG level at the 120 -min interval $(4.48 \pm 0.36 \mathrm{mmol} / \mathrm{L}$ vs. $5.49 \pm 0.23 \mathrm{mmol} / \mathrm{L} ; p=0.040)$ when compared with the control. However, SCH4.2 illustrated significant reduction in BG level at the 60-min interval $(3.57 \pm 0.27$ $\mathrm{mmol} / \mathrm{L}$ vs. $4.59 \pm 0.21 \mathrm{mmol} / \mathrm{L} ; p=0.017$ ); substantial improvement in postprandial glucose tolerance was also observed from the 90 - $\mathrm{min}(4.74 \pm 0.38 \mathrm{mmol} / \mathrm{L}$ vs $5.74 \pm$ $0.14 \mathrm{mmol} / \mathrm{L} ; \quad p=0.040)$ to the $150-\mathrm{min}(3.89 \pm 0.33$ $\mathrm{mmol} / \mathrm{L}$ vs. $5.10 \pm 0.30 \mathrm{mmol} / \mathrm{L} ; p=0.025)$ interval when compared with the control. A comparison of $\mathrm{SCH} 4.1$ with glibenclamide highlighted that $\mathrm{SCH} 4.1$ had a comparable effect on the glycaemic response at the 120-min interval ( $p>0.05$; Fig. 3$)$. SCH4.2 also had a comparable effect on the glycaemic response to that displayed by glibenclamide at the 60 and 90 -min intervals $(p>0.05$; Fig. 3$)$.
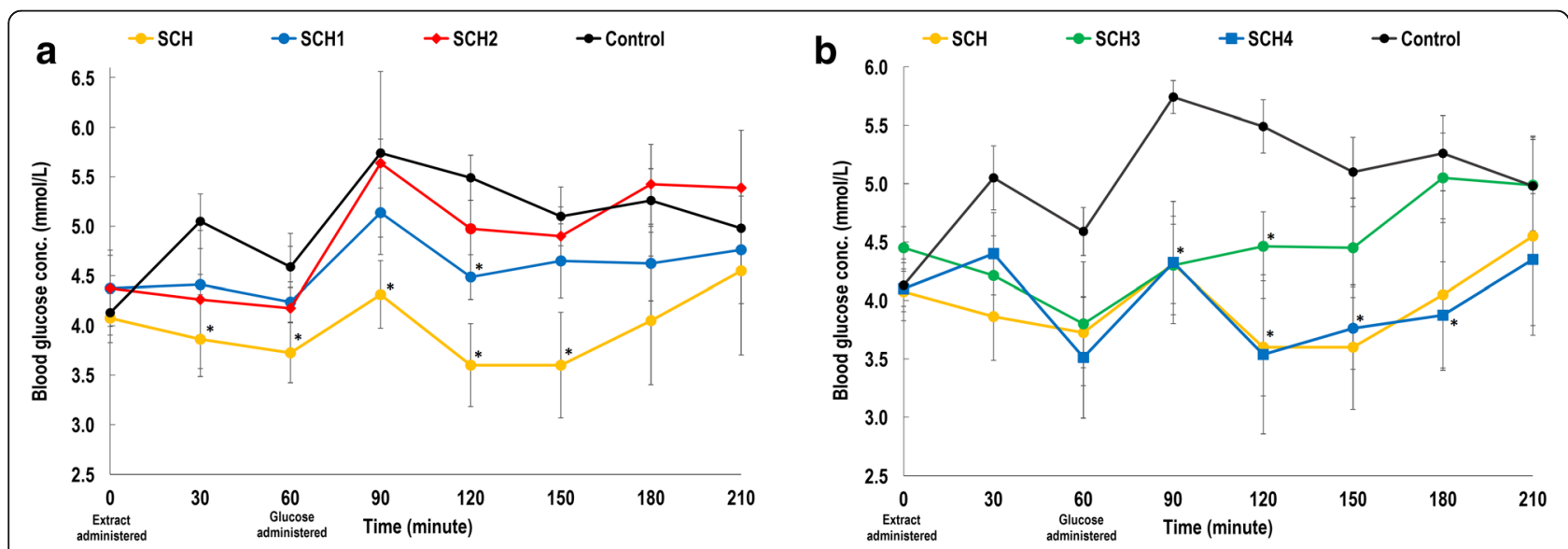

Fig. 1 a Effect of Smilax canellifolia rhizomes hexane crude extract (SCH; 50 mg/kg BW) and sub-fractions (SCH1-SCH2; 25 mg/kg BW) on blood glucose concentration. Data expressed as mean \pm SEM $(n=5)$; * represents $p<0.05$ vs control. b. Effect of SCH $(50 \mathrm{mg} / \mathrm{kg} \mathrm{BW})$ and sub-fractions $(\mathrm{SCH} 3-\mathrm{SCH} 4 ; 25 \mathrm{mg} / \mathrm{kg} \mathrm{BW})$ on blood glucose concentration. Data are mean $\pm \mathrm{SEM}(n=5)$; ${ }^{*}$ represents $p<0.05$ vs control 


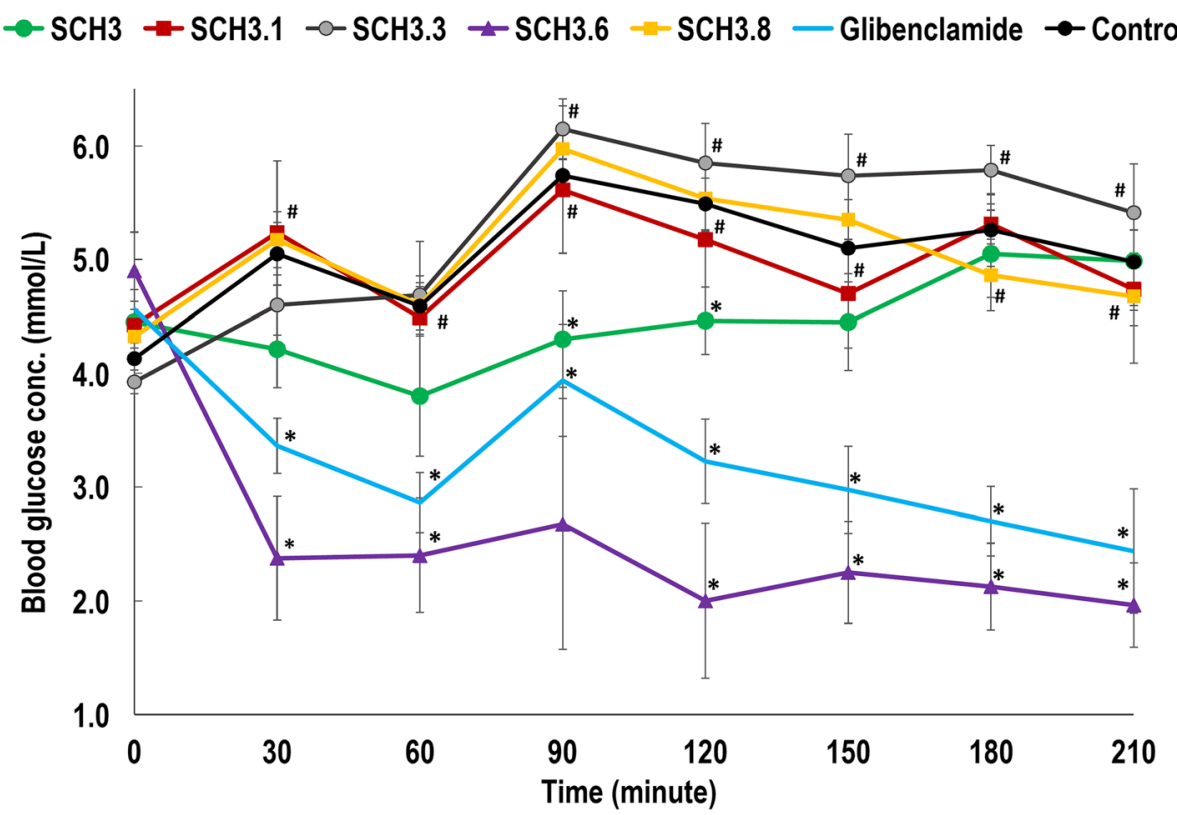

Fig. 2 Effect of sub-fractions (10 mg/kg BW) from SCH3 and glibenclamide (5 mg/kg BW) on blood glucose concentration. Data expressed as mean $\pm \operatorname{SEM}(n=5) ;{ }^{*}$ represents $p<0.05$ vs control and \# represent $p<0.05$ vs glibenclamide

\section{Spectroscopic identification}

\section{Sub-fraction SCH3.6}

SCH3.6 was isolated as white needle-shaped crystals (m.p. $133-136^{\circ} \mathrm{C}$ ) upon recrystallization in cold ethyl acetate. The IR absorption spectrum of SCH3.6 showed absorption peaks at $3361.86 \mathrm{~cm}^{-1}\left(\mathrm{OH}\right.$ stretching), $2950 \mathrm{~cm}^{-1}$, $2850 \mathrm{~cm}^{-1}$ (C-H stretching), $1379 \mathrm{~cm}^{-1}, 1368 \mathrm{~cm}^{-1}$ (C-H stretching; geminal dimethyl), $1709 \mathrm{~cm}^{-1}$ ( $\mathrm{C}=\mathrm{O}$ stretching), $1464 \mathrm{~cm}^{-1}$ (C-H bending, methyl group), $971 \mathrm{~cm}^{-1}, 959$ $\mathrm{cm}^{-1}$ (di-substituted trans $\mathrm{C}=\mathrm{C}$ bending) and $1048 \mathrm{~cm}^{-1}$, $1022 \mathrm{~cm}^{-1}$. Other bands present at $882 \mathrm{~cm}^{-1}, 839 \mathrm{~cm}^{-1}$, and $780 \mathrm{~cm}^{-1}$ (tri-substituted $\mathrm{C}-\mathrm{H}$ bending).

${ }^{1} \mathrm{H}$ NMR data confirmed the steroidal nature of the compound(s) in SCH3.6 were due to the characteristic

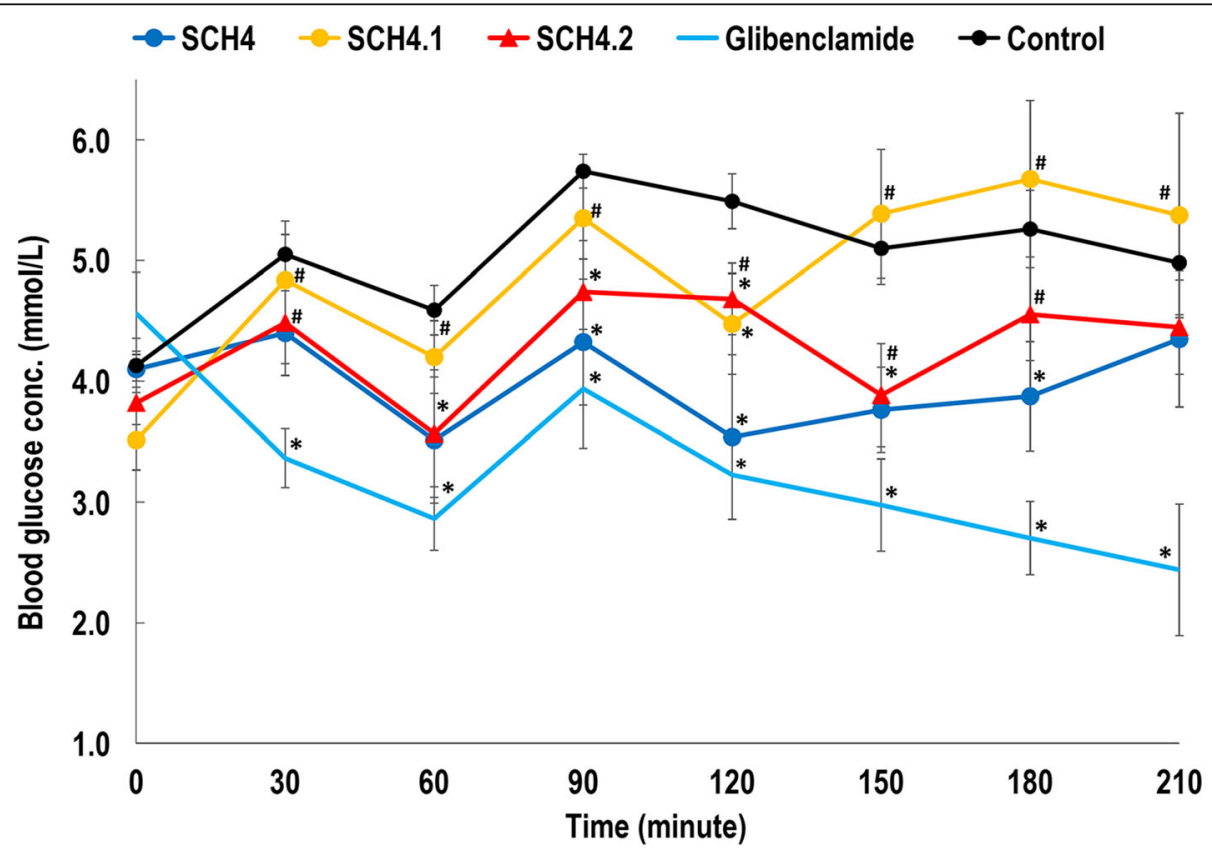

Fig. 3 Effect of sub-fractions (10 mg/kg BW) from SCH4 and glibenclamide ( $5 \mathrm{mg} / \mathrm{kg} \mathrm{BW}$ ) on blood glucose concentration. Data expressed as mean $\pm \operatorname{SEM}(n=5)$; ${ }^{*}$ represents $p<0.05$ vs control and \# represent $p<0.05$ vs glibenclamide 
cluster of proton peaks in the $0.50-2.50 \mathrm{ppm}$ region. The data showed the presence of two non-protonated carbons, two methines, nine methylenes, and six methyls. The methyl singlets were seen at $\delta=0.68$ (s, $3 \mathrm{H})$ and $\delta=1.03(\mathrm{~s}, 3 \mathrm{H})$ representing the angular methyl groups at C28and C29, respectively. Two geminal methyl groups were also observed at $\delta=0.87(\mathrm{~d}, 3 \mathrm{H})$ and $\delta=$ $0.87(\mathrm{~d}, 3 \mathrm{H})$ for $\mathrm{C} 26$ and $\mathrm{C} 27$, respectively. At $\mathrm{C} 19$, the methyl was a doublet at $\delta=0.94(\mathrm{~d}, 3 \mathrm{H})$, and a terminal methyl at $\mathrm{C} 24$ occurred at $\delta=0.87(\mathrm{t}, 3 \mathrm{H})$. SCH3.6 also showed protons at $\delta=5.01(\mathrm{~m}, 1 \mathrm{H}), \delta=5.15(\mathrm{~m}, 1 \mathrm{H})$, and $\delta=5.37(\mathrm{t}, 1 \mathrm{H})$ which suggested the presence of a trisubstituted olefinic bond and disubstituted olefinic bond. The trisubstituted proton signal correlated with a double bond system at $\mathrm{C} 20 / \mathrm{C} 21$, while the latter proton signal corresponded to the double bond at C5/C6. The signal occurring at $\delta=5.37$ (tdd, $1 \mathrm{H}$ ) corresponded to the $\mathrm{H}-3$ of the oxymethine moiety of a sterol. The appearance of mirror shifts in the ${ }^{13} \mathrm{C}$ NMR spectra (Table 1) alluded to the presence of two similar compounds and was consistent with the literature [22].

GC-MS analysis indicated that SCH3.6 contained several components, however, two were present in greater proportions (See supplemental file, Fig. 1S). The mass spectrum of the peak A, (retention time [RT], $16.21 \mathrm{~min}$ ) showed a weak molecular ion peak at $\mathrm{m} / \mathrm{z} 484$ which corresponded to the molecular formula $\mathrm{C}_{32} \mathrm{H}_{56} \mathrm{OSi}[\mathrm{M}$ $\left.{ }^{+}\right]$, other peaks observed at $\mathrm{m} / \mathrm{z} 469\left[\mathrm{M}^{+}-\mathrm{Me}\right], 394$ $\left[\mathrm{M}^{+}-\mathrm{C}_{6} \mathrm{H}_{18}\right], 379\left[\mathrm{M}^{+}-\mathrm{C}_{7} \mathrm{H}_{21}\right], 129,83,55$. Peak B (RT, $17.01 \mathrm{~min}$ ) had a molecular ion peak at $\mathrm{m} / \mathrm{z} 486$ $\left[\mathrm{M}^{+}\right]$, which corresponded to the molecular formula $\mathrm{C}_{32} \mathrm{H}_{58} \mathrm{OSi}\left[\mathrm{M}^{+}\right]$. Other ion peaks were observed at $\mathrm{m} / \mathrm{z}$ $471\left[\mathrm{M}^{+}-\mathrm{Me}\right], 396\left[\mathrm{M}^{+}-\mathrm{C}_{6} \mathrm{H}_{18}\right], 381\left[\mathrm{M}^{+}-\mathrm{C}_{7} \mathrm{H}_{21}\right], 129$, 73, 57. Spectrometric analyses along with $\mathrm{GC}$ area percentage (\%) identified peaks A and B as the trimethylsilyl (TMS) derivatives of stigmasterol (compound (1); 15.26\%) and $\beta$-sitosterol (compound (2); 35.56\%). These phytosterols were the major components of SCH3.6 (Fig. 4). The remaining components consisted of medium and shortchain fatty acids, primarily palmitic acid $(8.55 \%)$ and oleic acid (3.5\%). Reference standards for stigmasterol trimethylsilyl ether (RT, $16.10 \mathrm{~min}$ ) and $\beta$-sitosterol trimethylsilyl ether (RT, $16.96 \mathrm{~min}$ ) also produced identical MS fragment ions.

\section{Sub-fraction $\mathrm{SCH} 4.2$}

SCH4.2 (m.p. $63-68^{\circ} \mathrm{C}$ ) was isolated as an aggregate of off-white amorphous solid embedded in a colourless oil. IR absorption was observed at $2915 \mathrm{~cm}^{-1}$ and 2849 $\mathrm{cm}^{-1}$ (C-H stretching), $1706 \mathrm{~cm}^{-1}$ ( $\mathrm{C}=\mathrm{O}$ stretching), $1464 \mathrm{~cm}^{-1}$ (C-H bending; methylene), $1411 \mathrm{~cm}^{-1}(\mathrm{O}-\mathrm{H}$ bending). The peaks were characteristic of fatty acids.

GC-MS analysis indicated that SCH4.2 contained several fatty acids (compounds $3-5$ ), which accounted
Table $1{ }^{13} \mathrm{C}$ NMR chemical shift values (ppm) of stigmasterol and $\beta$-sitosterol recorded in $\mathrm{CDCl}_{3}$

\begin{tabular}{|c|c|c|c|c|}
\hline \multirow[t]{2}{*}{ Carbons } & \multicolumn{2}{|c|}{ Stigmasterol } & \multicolumn{2}{|c|}{$\beta$-sitosterol } \\
\hline & Observed & Literature & Observed & Literature \\
\hline 1 & 37.3 & 37.6 & 36.5 & 37.5 \\
\hline 2 & 31.9 & 32.1 & 31.7 & 31.9 \\
\hline 3 & 71.8 & 72.1 & 71.8 & 72.0 \\
\hline 4 & 42.8 & 42.4 & 42.3 & 42.5 \\
\hline 5 & 140.8 & 141.1 & 140.7 & 140.9 \\
\hline 6 & 121.8 & 121.8 & 121.8 & 121.9 \\
\hline 7 & 31.9 & 31.8 & 31.9 & 32.1 \\
\hline 8 & 31.9 & 31.8 & 31.9 & 32.1 \\
\hline 9 & 50.2 & 50.2 & 50.1 & 50.3 \\
\hline 10 & 36.5 & 36.6 & 36.2 & 36.7 \\
\hline 11 & 21.2 & 21.5 & 21.1 & 21.3 \\
\hline 12 & 39.8 & 39.9 & 39.7 & 39.9 \\
\hline 13 & 42.3 & 42.4 & 42.2 & 42.6 \\
\hline 14 & 56.9 & 56.8 & 56.8 & 56.9 \\
\hline 15 & 24.4 & 24.4 & 26.0 & 26.3 \\
\hline 16 & 29.1 & 29.3 & 28.3 & 28.5 \\
\hline 17 & 56.0 & 56.2 & 56.1 & 56.3 \\
\hline 18 & 40.5 & 40.6 & 36.2 & 36.3 \\
\hline 19 & 23.1 & 21.7 & 19.0 & 19.2 \\
\hline 20 & 138.4 & 138.7 & 33.9 & 34.2 \\
\hline 21 & 129.3 & 129.6 & 26.0 & 26.3 \\
\hline 22 & 45.8 & 46.1 & 45.8 & 46.1 \\
\hline 23 & 25.4 & 24.4 & 23.1 & 23.3 \\
\hline 24 & 12.1 & 12.1 & 11.9 & 12.2 \\
\hline 25 & 29.1 & 29.6 & 28.9 & 29.4 \\
\hline 16 & 21.1 & 20.2 & 19.9 & 20.1 \\
\hline 27 & 19.9 & 19.8 & 19.4 & 19.6 \\
\hline 28 & 18.8 & 18.9 & 19.0 & 19.0 \\
\hline 29 & 12.3 & 12.2 & 12.0 & 12.0 \\
\hline
\end{tabular}

for greater than $75 \%$ of the total area percentage (See supplemental file, Fig. 2S). MS data of peak A (RT, $12.86 \mathrm{~min}$ ) showed a weak molecular ion peak at $\mathrm{m} / \mathrm{z}$ 328 which corresponded to the molecular formula $\mathrm{C}_{19} \mathrm{H}_{40} \mathrm{OSi}\left[\mathrm{M}^{+}\right]$, other peaks were observed at $\mathrm{m} / \mathrm{z} 313$ $\left[\mathrm{M}^{+}-\mathrm{Me}\right], 285\left[\mathrm{M}^{+}-\mathrm{Pr}\right], 145,132,129,117,73$. Peak B (RT, $13.72 \mathrm{~min}$ ) with the molecular ion peak at $\mathrm{m} / \mathrm{z} 354$ $\left[\mathrm{M}^{+}\right]$corresponded to the molecular formula $\mathrm{C}_{18} \mathrm{H}_{34} \mathrm{OSi}$ $\left[\mathrm{M}^{+}\right]$. Other ion peaks were observed at $\mathrm{m} / \mathrm{z} 339\left[\mathrm{M}^{+}\right.$ $\mathrm{Me}$, $264\left[\mathrm{M}^{+}-\mathrm{C}_{6} \mathrm{H}_{18}\right], 145,129,117,73$. Peak C (RT, $13.83 \mathrm{~min})$ molecular ion peak at $\mathrm{m} / \mathrm{z} 356\left[\mathrm{M}^{+}\right]$corresponded to the molecular formula $\mathrm{C}_{18} \mathrm{H}_{36} \mathrm{OSi}\left[\mathrm{M}^{+}\right]$; other ion peaks were observed at $\mathrm{m} / \mathrm{z} 341\left[\mathrm{M}^{+}-\mathrm{Me}\right]$, $313\left[\mathrm{M}^{+}-\mathrm{Pr}\right], 145,132,117,73$. MS data and GC area $\%$ identified peaks A, B and C as the TMS derivatives of 


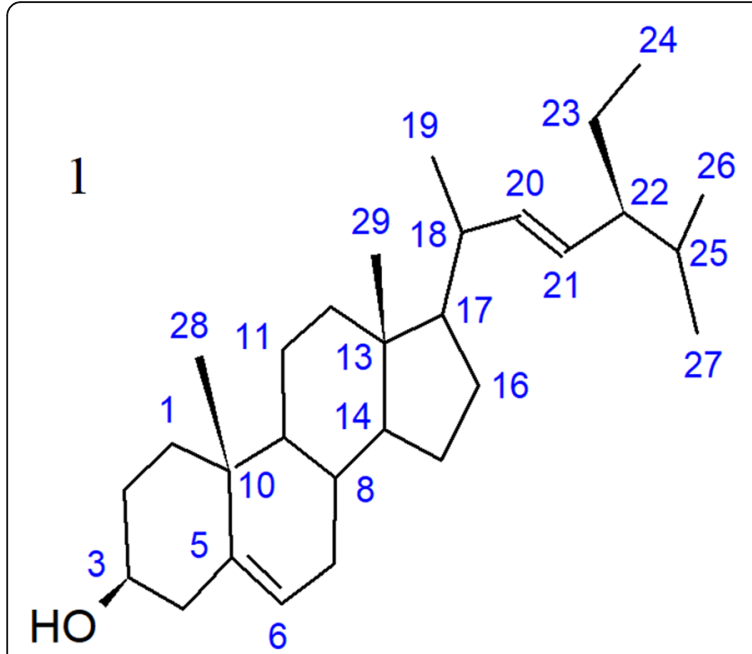

Fig. 4 Structure of stigmasterol (1) and $\beta$-sitosterol (2)

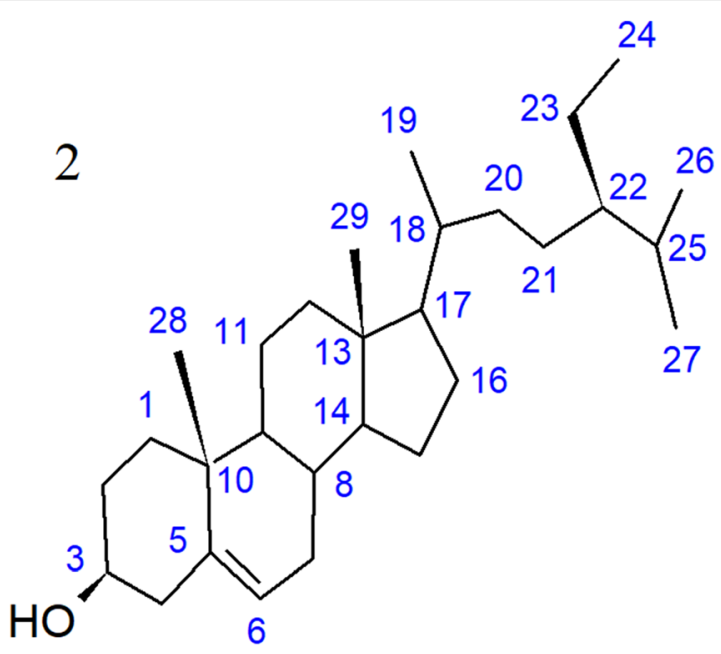

hexadecanoic acid (42.11\%) and (9Z)-octadec-9-enoic acid (31.84\%) and octadecanoic acid (5.84\%) which were the major components of SCH4.2 (Fig. 5). Reference standards for hexadecanoic acid, trimethylsilyl ester (palmitic acid, TMS derivative; RT, $12.93 \mathrm{~min}$ ), (9Z)octadec-9-enoic acid, trimethylsilyl ester (oleic acid, (Z)-, TMS derivative; RT, $13.86 \mathrm{~min}$ ) and octadecanoic acid, trimethylsilyl ester (stearic acid, TMS derivative; RT, 13.94 $\mathrm{min}$ ) also produced identical MS fragment ions.

\section{Discussion}

A survey that was conducted in Jamaica highlighted the popularity of self-medicating with traditional medicine for the treatment of common ailments and chronic diseases, including diabetes and hypertension [23]. The rhizomes of Smilax canellifolia, though commonly used as a general health tonic and aphrodisiac has been noted in folklore to be beneficial in the treatment of diabetes $[8,9]$. Smilax species have made significant contributions

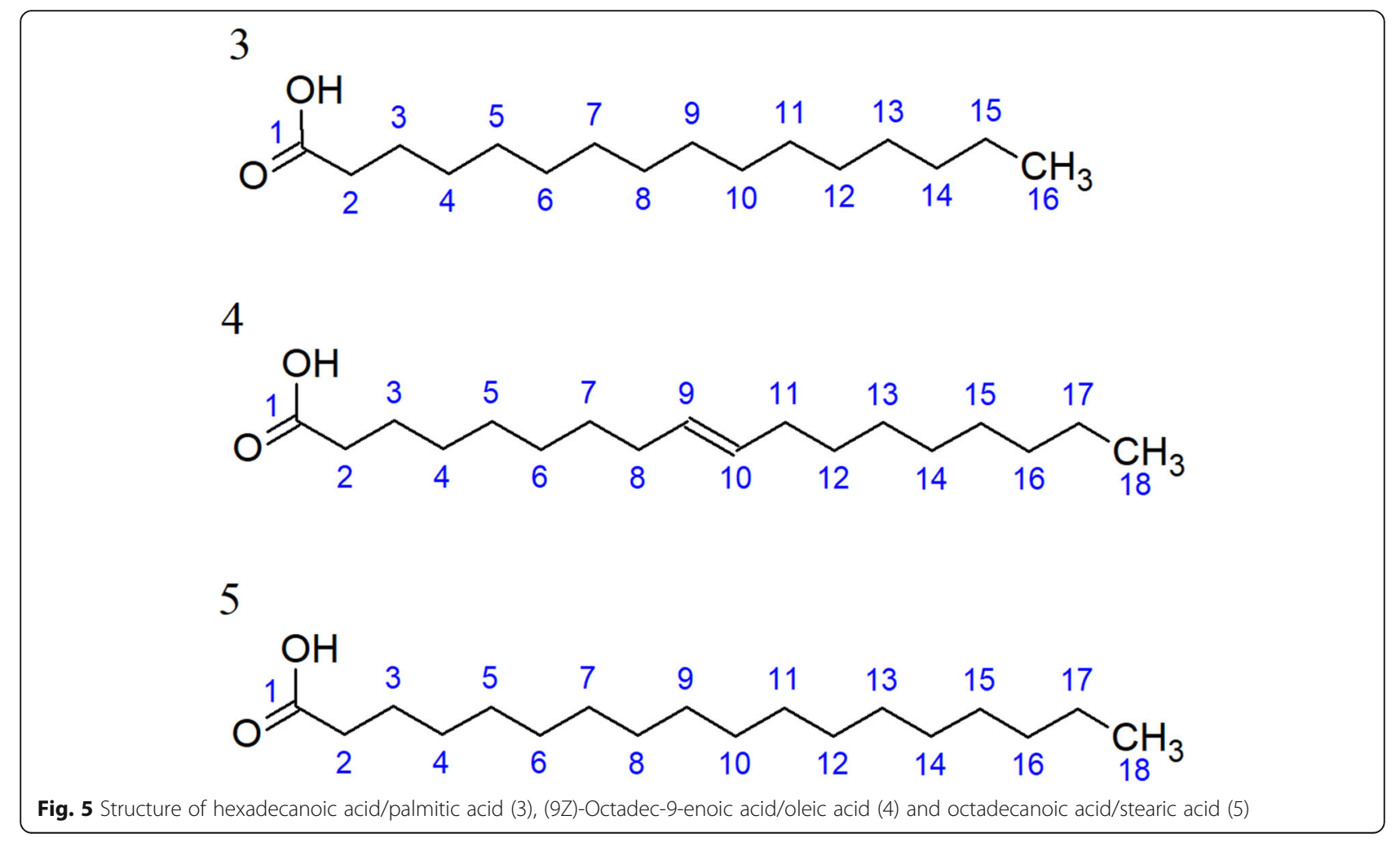


as alternative interventions for the treatment of hyperglycaemia, hypertension, and oxidative stress, which are all associated with diabetes [13-15, 18, 24].

This study conducted hypoglycaemic screening on the hexane crude extract of $S$. canellifolia rhizomes in normoglycaemic rats, which highlighted that intravenous administration $(50 \mathrm{mg} / \mathrm{kg} \quad \mathrm{BW})$ produced significant hypoglycaemic responses (Fig. 1a). The reduced glycaemic peak observed at the 90-min interval indicated that the extract contained compounds that were able to enhance blood glucose clearance. In previous investigations, the hexane crude extract was found to exert the most potent hypoglycaemic effect from a group of three solvent extracts (hexane, ethyl acetate and methanol) that were screened. The prolonged hypoglycaemic effect displayed by the hexane crude extract $(\mathrm{SCH})$ when compared with the other extracts was significant and therefore, it was consequently subjected to bioassay-guided purification [20, 25]. In contrast, other Smilax species such as $S$. aristolochiifolia and S. moranensis indicated that their polar solvent extracts (methanol or ethanolwater) produced the most potent hypoglycaemic effects $[13,26,27]$. These studies also focused on other parts of the plant (leaves and roots) and indicated that the bioactive compounds were possibly flavonoids, alkaloids, and polyphenols - some of which were absent in our hexane extract from S. canellifolia rhizomes, possibly due to the variation in polarity [25].

Further screening of the semi-purified fractions (25 $\mathrm{mg} / \mathrm{kg} \mathrm{BW}$; intravenous administration) from $\mathrm{SCH}$, illustrated that $\mathrm{SCH} 3$ and $\mathrm{SCH} 4$ were significant in their ability to lower the postprandial glycaemic responses during the OGTT (Figure 1b). Studies have found that therapeutics that target postprandial hyperglycaemia were beneficial in the initial treatment of diabetes as they reduce the formation of glycated-end products and oxidative stress $[28,29]$. Therefore, natural products that can manage this glycaemic spike may have significant potential as alternative medicines used for diabetes.

Chromatography purification of $\mathrm{SCH} 3$ and $\mathrm{SCH} 4$ led to the isolation of phytosterols (SCH3.6) and fatty acids (SCH4.2), respectively as revealed by spectroscopy analyses. They were identified as the key naturally isolated compounds to which the hypoglycaemic activities were attributed. It has been noted that the various pharmacological activities displayed by Smilax species could, in part, be linked to the presence of phytosterols that enhanced the absorption and bioavailability of other phytochemicals and drugs [30].

Sub-fraction SCH3.6 $(10 \mathrm{mg} / \mathrm{kg} \mathrm{BW}$; intravenous administration) displayed significant hypoglycaemia when compared with the control (Fig. 2). GC-MS analysis identified the main constituents of this sub-fraction as a mixture of stigmasterol and $\beta$-sitosterol, with several fatty acids making up the remaining minority (Fig. 4). Stigmasterol and $\beta$-sitosterol are sterols (steroid alcohols) found mainly in plants (phytosterols), with structural similarity to cholesterol [31]. These sterols differ from cholesterol with the addition of an ethyl group in their side chain, while the unsaturation at carbon 20-21 of stigmasterol distinguishes it from $\beta$-sitosterol. Phytosterols are utilized as precursors/ intermediate molecules in plant development and cell signaling [32]. Studies have highlighted that stigmasterol and $\beta$-sitosterol exhibit antidiabetic and hypoglycaemic effects in both diabetic and healthy animals respectively[33, 34]. They also have potential antioxidative, hepatoprotective, and anti-inflammatory effects [35]. In this study, the hypoglycaemic effect observed throughout the OGTT could be linked to the phytosterols' stimulatory effects on insulin secretion [30, 36]. This hypoglycaemic effect may also be independent of BG concentration, as observed with the significant lowering in the animals' fasted BG levels (Fig. 2). Jamaluddin et al. suggested that the hypoglycaemic effect of these phytosterols in Parkia speciosa was due to their synergistic action. When orally administered to diabetic rats, each individual phytosterol failed to cause significant hypoglycaemia [33]. In our study these naturally occurring phytosterols, when administered (intravenously) in combination, also produced significant BG concentration reduction in normoglycaemic S-D rats. The effect observed may have been due to the evasion of the first-pass metabolism, which could have contributed to the rapid onset of hypoglycaemia, as observed in the fasted state.

SCH4.2 was found to contain palmitic acid (PA), oleic acid (OA) and stearic acid (SA). Although these fatty acids (FAs) have been identified in Smilax species, their occurrence has never been reported as the components contributing to their hypoglycaemic activity [37]. Fatty acids are carboxylic acids with hydrophobic hydrocarbon chains that are categorized based on the absence (saturated FA) or presence and position of double bonds (unsaturated; cis and trans) along these chains. The length of these FA chains also determines their physiological use as high energy sources and cell membrane components [38]. PA and SA are bothsaturated fatty acids while $\mathrm{OA}$ is a monounsaturated fatty acid. A balanced ratio (saturated : unsaturated ) of these three fatty acids will ensure the homeostatic functioning of membrane phospholipids that are vital in regulating intracellular signaling and maintaining membrane structure and fluidity [38]. This balance also reduces the risks of cardiovascular diseases, hyperglycaemia and inflammatory events due to an accumulation of saturated FAs, especially PA [39]. Free fatty acids (FFAs) are known to increase insulin secretion at elevated glucose concentrations [40, 41]. While OA and PA can enhance insulin secretion at physiologically low BG levels, this 
effect is more apparent with monounsaturated FAs [42]. This insulin-independent effect may have accounted for the reduction observed in the fasted state (60-min interval; Fig. 3). Our findings indicated that the administration of SCH4.2, containing primarily PA, OA, and SA, was able to produce a significant reduction in the postprandial BG levels. The FAs were determined to occur at a ratio of 7:5:1 naturally, and their hypoglycaemic effect may have been in response to the synergistic action of the FFAs and their impact on insulin release [40]. Daley-Beckford et al. conducted a similar study using healthy normoglycaemic S-D rats [43]. They concluded that a mixture of PA and OA in the ratio of 2.3:1 from Eucalyptus camaldulensis was able to improve glucose tolerance (postprandial). The glycaemic control produced was associated with an increase in insulin secretion in the animals. Moreover, PA and OA were also found to contribute to the antidiabetic effect observed in Juniperus oxycedrus leaves [44]. Studies have indicated that the hypoglycaemic effect observed with the administration of these fatty acids could also be associated with their ability to trigger GLUT-4 translocation in rat skeletal muscles $[45,46]$. This fatty acid-stimulated glucose uptake was linked to increased phosphorylation of signaling proteins, which are critical components in GLUT-4 translocalization [45-47]. These findings suggest that an increase in GLUT-4 mediated glucose uptake and insulin secretion could be the primary mechanism ofhypoglycaemiafor the fatty acids identified in this study [45].

\section{Conclusion}

This study has established that several compounds present in the hexane sub-fractions of Smilax canellifolia rhizomes had a synergistic hypoglycaemic effect. These compounds were identified as stigmasterol, $\beta$-sitosterol, and the fatty acids: palmitic acid, oleic acid, and stearic acid. It was evident that these naturally occurring compounds contributed to an improvement in postprandial glucose tolerance, which led to significant hypoglycaemic activity when administered to Sprague-Dawley rats. This is the first report on the purification, isolation and identification of the hypoglycaemic compounds from $S$. canellifolia rhizomes. Overall, the presence of these bioactive constituents in $S$. canellifolia rhizomes add credence to its use in folklore medicine. We, therefore, propose to further ascertain the antidiabetic and physiological effects of these constituents in a diabetic animal model. Smilax canellifolia rhizomes have the potential to be used as a phytopharmaceutical or nutraceutical in the management of diabetes.

\section{Abbreviations}

BG: Blood glucose; BSTFA: Bis-(trimethylsilyl)-trifluoroacetamide:

DMSO: Dimethyl sulfoxide; FFAs: Free fatty acids; FAs: Fatty acids; OA: Oleic acid; OGTT: Oral Glucose Tolerance Test; PA: Palmitic acid; RT: Retention time; S. canellifolia: Smilax canellifolia Mill.; SCH: Smilax canellifolia rhizomes hexane crude extract; S-D: Sprague-Dawley; SA: Stearic acid; TMS: Tetramethylsilane; UWl: University of the West Indies

\section{Supplementary Information}

The online version contains supplementary material available at https://doi. org/10.1186/s40816-021-00325-w.

Additional file 1.

\section{Acknowledgements}

The authors thank Mr. Edwin Peddie for providing the plant material, Mr. Patrick Lewis and Dr. Ena Vandebroek for their assistance in identifying and authenticating the plant. A special Conceptualization and methodology, software, validation, formal analysis, investigation, resources, datathanks to Ms. Dolesha Davis for assisting with the spectroscopic analysis.

\section{Authors' contributions}

D.P.: Conceptualization and methodology, software, validation, formal analysis, investigation, resources, datacuration, writing-original draft preparation and writing - review and editing. S.B.: validation, formal analysis and writing - review and editing. S.F.: formal analysis and writing-review and editing. R.A.L.: Conceptualization and methodology, validation, formal analysis, resources, writing — review and editing and supervision. The authors have read and approved the final manuscript.

\section{Funding}

The authors received no external financial support for the research, authorship, and/or publication of this article. The authors acknowledge the Office of Graduate Studies and Research, the UWI, Mona, for the grant used to obtain the reagents and material to conduct this research.

\section{Availability of data and materials}

The authors declare that [the/all other] data supporting the findings of this study are available within the article [and its supplementary information files].

\section{Declarations}

Ethics approval and consent to participate

The protocol used in this study was approved by the UWI, Mona Campus Research Ethics Committee (Reference No. AN, 8, 14/15).

\section{Consent for publication}

Not applicable.

\section{Competing interests}

The authors declare that they have no competing interests.

\section{Author details}

${ }^{1}$ Department of Basic Medical Sciences, Faculty of Medical Sciences, The University of the West Indies (UWI), Mona, Kingston 7, Jamaica. ${ }^{2}$ Natural Products Institute, Faculty of Science and Technology, The University of the West Indies (UWI), Mona, Kingston 7, Jamaica.

Received: 13 June 2021 Accepted: 1 November 2021

Published online: 18 November 2021

\section{References}

1. Zhang Q. Global situation and WHO strategy on traditional medicine. Tradit Med Mod Med. 2018;01(01):11-3.

2. Bhagour K, Arya D, Gupta RS. A review: antihyperglycemic plant medicines in management of diabetes. Acupunct Relat Ther. 2016:4(4):7-16.

3. Addae-Mensah I, Fakorede F, Holtel A, Nwaka S. Traditional medicines as a mechanism for driving research innovation in Africa. Malar J. 2011;10(Suppl. 1):1-4.

4. Živković J, llić M, Zdunić G, Jovanović-Lješković N, Menković N, Šavikin K. Traditional use of medicinal plants in Jablanica district (south-eastern 
Serbia): ethnobotanical survey and comparison with scientific data. Genet Resour Crop Evol. 2021;68(4):1655-74.

5. Cahyaningsih R, Magos Brehm J, Maxted N. Setting the priority medicinal plants for conservation in Indonesia. Genet Resour Crop Evol. 2021;68(5): 2019-50.

6. Yuan $\mathrm{H}, \mathrm{Ma}$ Q, Ye L, Piao $\mathrm{G}$. The traditional medicine and modern medicine from natural products. Molecules. 2016;21(5):559.

7. Vandebroek I, Picking D, Tretina J, West J, Grizzle M, Sweil D, et al. Root tonics and resilience: building strength, health, and heritage in Jamaica. Front Sustain Food Syst. 2021;5:42.

8. Mitchell SA. The Jamaican root tonics: a botanical reference. Focus Altern Complement Ther. 2011;16(4):271-80.

9. Mitchell SA, Ahmad MH. Morphology, horticulture and biotechnology of root tonic non-timber forest species of Jamaica including the endemic plant, Chainy Root (Smilax balbisiana). In: 1st International Symposium on Tropical Horticulture. Kingston, Jamaica; 2010. p. 42.

10. Adams CD. Flowering plants of Jamaica. Mona: University of the West Indies; 1972.

11. Bulgin-Graham A-M. Chaney Root Medicinal Herb | Jamaican Tonic Medicinalherbs-4u.com [Internet]. [cited 2020 Aug 6]. Available from: https:// www.medicinalherbs-4u.com/chaney-root.htm

12. Mitchell SA, Ahmad MH. A review of medicinal plant research at the University of the West Indies, Jamaica, 1948-2001. West Indian Med J. 2006; 55(4):243-69.

13. Amaro CAB, González-Cortazar M, Herrera-Ruiz M, Román-Ramos R, AguilarSantamaría L, Tortoriello J, et al. Hypoglycemic and hypotensive activity of a root extract of Smilax aristolochifolia, standardized on N-trans-feruloyltyramine. Molecules. 2014;19(8):11366-84.

14. Andrade-Cetto A. Hypoglycemic effect of Smilax moranensis root on N5STZ diabetic rats. Pharmacologyonline. 2011;1:111-5.

15. Challinor VL, Parsons PG, Chap S, White EF, Blanchfield JT, Lehmann RP, et al. Steroidal saponins from the roots of Smilax sp.: structure and bioactivity. Steroids. 2012;77(5):504-11.

16. Fukunaga T, Miura T, Furuta K, Kato A. Hypoglycemic effect of the rhizomes of Smilax glabra in normal and diabetic mice. Biol Pharm Bull. 1997;20(1): 44-6.

17. Lee SE, Ju EM, Kim JH. Free radical scavenging and antioxidant enzyme fortifying activities of extracts from Smilax China root. Exp Mol Med. 2001; 33(4):263-8

18. Solomon Raju BG, Ganga Rao B, Manju Latha YB. Antidiabetic activity of Smilax China roots in alloxan-induced diabetic rats. Int J PharmTech Res. 2012:4(1):369-74.

19. Peddie DA, Alexander-Lindo RL. The effect of Smilax balbisiana (Chainy Root) on blood glucose concentration and haemodynamic parameters in normal Sprague-Dawley rats. In: Faculty of Medical Sciences 25th Annual Research Conference and Workshop on One Health, One Caribbean. Kingston: Faculty of Medical Sciences, The University of the West Indies, Mona, Jamaica; 2016. p. 49

20. Peddie D, Bryan S, Alexander-Lindo R. Hypoglycaemic potential of Smilax balbisiana (Chainy Root) extracts in normal, healthy Sprague- Dawley rats. In: The University Diabetes Outreach Program 23rd International Conference, Diabetes and the Skin: Be Aware. St. Ann: Scientific Research Council, Jamaica; 2017. p. 34

21. Wilson RD, Islam MS. Fructose-fed streptozotocin-injected rat: an alternative model for type 2 diabetes. Pharmacol Rep. 2012:64(1):129-39.

22. Sai V, Chaturvedula P, Prakash I. Isolation of stigmasterol and $\beta$-sitosterol from the dichloromethane extract of Rubus suavissimus. Int Curr Pharm J. 2012;1(9):239-42

23. Picking D, Younger N, Mitchell S, Delgoda R. The prevalence of herbal medicine home use and concomitant use with pharmaceutical medicines in Jamaica. J Ethnopharmacol. 2011;137(1):305-11.

24. Seo HK, Lee JH, Kim HS, Lee CK, Lee SC. Antioxidant and antimicrobial activities of Smilax China L. leaf extracts. Food Sci Biotechnol. 2012;21(6): $1723-7$

25. Peddie DA, Bowen-Forbes CS, Alexander-Lindo RL. The ethnopharmacological effects of crude extracts from Smilax balbisiana (Chainy root) rhizomes. Med Aromat Plants. 2020;9(6):1-6.

26. Romo-Pérez A, Escandón-Rivera SM, Andrade-Cetto A. Chronic hypoglycemic effect and phytochemical composition of Smilax moranensis roots. Rev Bras. 2019:29(2):246-53.
27. Pérez-Nájera VC, Gutiérrez-Uribe JA, Antunes-Ricardo M, Hidalgo-Figueroa S, Del-Toro-Sánchez CL, Salazar-Olivo LA, et al. Smilax aristolochiifolia root extract and its compounds chlorogenic acid and astilbin inhibit the activity of a-amylase and a-glucosidase enzymes. Evid Based Complement Alternat Med. 2018;2018:1-12.

28. Kim $Y M$, Jeong $Y K$, Wang $M H$, Lee WY, Rhee HI. Inhibitory effect of pine extract on a-glucosidase activity and postprandial hyperglycemia. Nutrition. 2005;21(6):756-61.

29. Su CH, Lai MN, Ng LT. Inhibitory effects of medicinal mushrooms on aamylase and a-glucosidase - enzymes related to hyperglycemia. Food Funct. 2013:4(4):644-9.

30. Taylor L. Technical data report for sarsaparilla Smilax officinalis. Austin: Sage Press Inc; 2003.

31. Ullah $\mathrm{H}$, Khan $\mathrm{H}$. Epigenetic drug development for autoimmune and inflammatory diseases. In: Histone Modifications in Therapy: Academic Press; 2020. p. 395-413.

32. Saeidnia S, Azadeh M, Ahmad G, Mohammed A. The story of beta-sitosterola review. European J Med Plants. 2014;4(5):590-609.

33. Jamaluddin F, Mohamed S, Lajis MN. Hypoglycaemic effect of Parkia speciosa seeds due to the synergistic action of $\beta$-sitosterol and stigmasterol. Food Chem. 1994;49(4):339-45.

34. Ramu R, Shirahatti PS, Nayakavadi S. R V, Zameer F, Dhananjaya BL, et al. the effect of a plant extract enriched in stigmasterol and $\beta$-sitosterol on glycaemic status and glucose metabolism in alloxan-induced diabetic rats. Food Funct. 2016;7(9):3999-4011.

35. Borse SP, Singh DP, Upadhyay D, Nivsarkar M. Potential synergistic effects of quercetin with other phytoconstituents of Costus pictus (insulin plant) extract in the control of hyperglycemia and prevention of NSAID-induced gastroenteropathy in diabetic rats. Food Chem Toxicol. 2018;120:448-61.

36. Mendes MF, David I, Bogle L. Evaluation of the effects and mechanisms of bioactive components present in hypoglycemic plants. Int J Chem Biomol Sci. 2015;1(3):167-78.

37. Delgado-Pelayo R, Hornero-Méndez D. Identification and quantitative analysis of carotenoids and their esters from sarsaparilla (Smilax aspera L.) berries. J Agric Food Chem. 2012;60(33):8225-32.

38. Calder PC. Functional roles of fatty acids and their effects on human health. J Parenter Enter Nutr. 2015:39(1 Suppl):18S-32S.

39. Moghadasian MH, Shahidi F. Fatty acids. In: International Encyclopedia of Public Health. 2nd ed: Elsevier; 2017. p. 114-22.

40. Fujiwara K, Maekawa F, Yada T. Oleic acid interacts with GPR40 to induce ca $2+$ signaling in rat islet $\beta$-cells: mediation by PLC and L-type ca $2+$ channel and link to insulin release. Am J Physiol Metab. 2005;289(4):E670-7.

41. Itoh $Y$, Kawamata $Y$, Harada M, Kobayashi M, Fujii R, Fukusumi S, et al. Free fatty acids regulate insulin secretion from pancreatic $\beta$ cells through GPR40. Nature. 2003;422(6928):173-6.

42. Campillo JE, Luyckx AS, Torres MD, Lefebvre PJ. Effect of oleic acid on insulin secretion by the isolated perfused rat pancreas. Diabetologia. 1979; 16(4):267-73.

43. Daley-Beckford DK. The isolation, purification and elucidation of the hypoglycaemic principles of Eucalyptus camaldulensis Dehnh. In: (Myrtaceae) and their hypotensive effect in normoglycaemic Sprague-Dawley rats: The University of the West Indies, Mona, Jamaica; 2013.

44. Orhan N, Aslan M, Demirci B, Ergun F. A bioactivity guided study on the antidiabetic activity of Juniperus oxycedrus subsp. oxycedrus L. leaves. J Ethnopharmacol. 2012:140(2):409-15.

45. Pu J, Peng G, Li L, Na H, Liu Y, Liu P. Palmitic acid acutely stimulates glucose uptake via activation of Akt and ERK1/2 in skeletal muscle cells. J Lipid Res. 2011;52(7):1319-27.

46. Kadan S, Saad B, Sasson Y, Zaid H. In vitro evaluation of anti-diabetic activity and cytotoxicity of chemically analysed Ocimum basilicum extracts. Food Chem. 2016:196:1066-74.

47. Benzler M, Benzler J, Stoehr S, Hempp C, Rizwan MZ, Heyward P, et al. "Insulin-like" effects of palmitate compromise insulin signalling in hypothalamic neurons. J Comp Physiol B. 2019;189(3):413-24.

\section{Publisher's Note}

Springer Nature remains neutral with regard to jurisdictional claims in published maps and institutional affiliations. 